\title{
Pelaporan Program Kemitraan Dan Bina Lingkungan Serta Corporate Social Re- sponsibility Badan Usaha Milik Negara
}

\author{
M ukti Fajar N D, Reni Budi Setyaningrum
}

DATA NASKAH

Masuk: 18 September 2017

Diterima: 24 November 2017

Terbit: 1 Desember 2017

KORESPONDEN PENULIS:

Fakultas Hukum Universitas

Muhammadiyah Yogyakarta

Jalan Lingkar Selatan Tamantirto

Kasihan Bantul Yogyakarta

muktifajar_umy@yahoo.co.id

\begin{abstract}
Act number 13 of 2003 on State 0 wned Enterprise obligate State 0 wned Enterprise to pay attention on social issues through Partnership and Community D evelopment Program (PKBL). M eanwhile Act number 40 of 2007 on the Limited Liability Company instruct Limited Liability Company to implement Social and Environmental Responsibility which often called as Corporate Social Responsibility (CSR). These two programs are practically have almost the same form, thus assign a double burden for SOE s on its implementation. This study aims are to find out the mechanism of implementation and reporting of PK BL and CSR from SOES which are both regulated in different legal regimes. This research is conducted normatively by reviewing various rules and legal documents and empirically by assessing various implementation of PK BL and C SR by SO Es. The result of this study indicate that SOE S must perform PK BL if they have profits, while $S O E$ s related to natural resources industry have to implement C SR which obtained from company's budget. Both programs are implemented in the same form in providing social assistance and community business. The C SR report is only reported in the Company's annual report to be accounted in front of $G$ eneral M eeting of Shareholders. While the aims of Partnership and Community Development Program financial reporting is to provide information on financial position, activity and cash flow statement and records, for stakeholder's decision making.

K eywords: Partnership and Community D evelopment Program, Corporate Social Responsibility, State-O wned Enterprises
\end{abstract}

\section{ABSTRAK}

U ndang U ndang Badan U saha M ilik Negara No 13 Tahun 2003 memberikan kewajiban bagi Perusahaan BU MN untuk memperhatikan 
persoalan social melalui Program Kemitraan dan Bina Lingkungan (PKBL). Sedangkan dalam U ndang U ndang Perseroan Terbatas No 40 Tahun 2007 mengamanatkan bagi perusahaan yang berbentuk Perseroan Terbatas untuk melakukan Tanggung Jawab Sosial dan Lingkungan atau sering disebut dengan Corporate Social Responsibilty (CSR). Sedangkan kedua program tersebut secara praktis bentuknya sama, sehingga memberikan beban ganda bagi BU MN untuk melaksanakannya. Penelitian ini bertujuan untuk mengetahui mekanisme pelaksanaan dan pelaporan PKBL dan CSR dari BU M N yang keduanya diatur dalam rejim hukum yang berbeda. Penelitian ini dilakukan secara normative dengan mengkaji berbagai aturan dan dokumen hukum serta dilakukan secara empiris dengan mengakaji berbagai pelaksanaan PKBL dan CSR oleh BU MN. Temuan dari penelitian ini menunjukan bahwa BUMN wajib melakukan PKBL jika ada keuntungan, sedangkan BU M N yang bergerak dibidang dan atau terkait dengan sumber daya alam wajib melaksanakan C SR bersumber dari anggaran. Kedua program tersebut dilaksanakan dalam bentuk yang hamper sama yaitu memberikan bantuan social dan usaha ekonomi masyarakat. Mekanisme pelaporan C SR hanya dimuat dalam laporan tahunan Perseroan dan dipertanggungjawabkan kepada RU PS. Sedangkan tujuan pelaporan keuangan Program Kemitraan dan Bina Lingkungan adalah menyediakan informasi posisi keuangan, aktivitas dan laporan arus kas serta catatan bagi pengguna dalam pengambilan keputusan.

Kata kunci: Program Kemitraan dan Bina Lingkungan, Corporate Social Responsibility, Badan U saha Milik Negara

\section{PENDAHULUAN}

Badan Usaha M ilik Negara (BUM N) selain mempunyai fungsi utama mencari keuntungan juga mempunyai tugas memperhatikan persoalan social. Dalam Pasal 88 ayat (1) Undang Undang No 19 Tahun 2003 tentang Badan Usaha Milik Negara (selanjutnya ditulis UU BUM N) disebutkan BUM N dapat menyisihkan sebagian laba bersihnya untuk keperluan pembinaan usaha kecil/koperasi serta pembinaan masyarakat sekitar BUM N.

Perwujudan Pasal 88 UUBUM N tersebut dilaksanakan melalui Program Kemitraan dan Bina Lingkungan (Selanjutnya disebut PKBL) dimana ketentuan terakhir diatur dalam Peraturan M enteri BUM N Nomor PER-02/M BU/7/ 2017 Tentang Perubahan Kedua Atas Peraturan menteri BUM N Nomor PER-09/M BU/07/ 2015 Tentang Program Kemitraan Dan Program Bina Lingkungan BUM N. Peraturan tersebut nmenyatakan bahwa maksud dan tujuan pendirian BUM N tidak hanya mengejar keuntungan melainkan turut aktif memberikan bimbingan dan bantuan kepada pengusaha golongan ekonomi lemah, koperasi dan masyarakat. (http:/ /bumn.go.id/perhutani/ halaman/162, 2017).

Tetapi disisi lain, BUM N merupakan salah satu bentuk Perseroan Terbatasyang juga memiliki tanggung jawab sosial perusahaan dan lingkungan atau sering disebut sebagai Corporate Social Responsibility (CSR). Dimana hal tersebut diatur secara khusus dalam Undang Undang No 40 Tahun 2007 tentang Perseroan Terbatas (Selanjutnya ditulis UUPT). Pasal 74 ayat 1, disebutkan bahwa perseroan yang menjalankan usahanya di bidang dan atau berkaitan dengan sumberdaya alam, wajib untuk melaksanakan kegiatan tanggung jawab sosial perusahaan dan lingkungan. (http:/ /www.republika.co.id/berita/csr/tanya-jawab-csr/12/01/09/ Ixiwvu-apa-perbedaan-cSr-dengan-pkbl). CSR ini merupakan investasi untuk mendukung terciptanya pembangunan berkelanjutan (sustainable development). (https:// www.pindad.com/csr-dan-pkbl, 2017). Tujuan pengaturan ini agar Perseroan berperan serta dalam pembangunan ekonomi berkelanjutan yang bertujuan mewujudkan pembangunan ekonomi guna meningkatkan kualitas kehidupan, lingkungan, komunitas setempat, dan masyarakat pada umumnya.(UUPT, 2007). Dari kedua regulasi diatas membuat BUMN memiliki kewajiban melaksanakan CSR sekaligus juga melaksanakan PKBL, dimana secara praktis keduanya memiliki aplikasi program yang sama untuk kepedulian social. Bahkan ada pendapat yang mengatakan bahwa Pasal 88 ayat (1) UU BUM N tersebut dapat dikatakan sebagai CSR karena memang kegiatan yang dimaksud dalam Pasal tersebut merupakan kegiatan-kegiatan yang tidakjauh berbeda dengan CSR. (Rika Dwi Setiawati dan Budi Hermono, 2016:3)

Kedua aturan yang berbeda mengenai CSR dan PKBL, menimbulkan beberapa persoalan. Pertama, dari sisi 
nomenklatur, CSR yang diatur dalam UUPT berbeda dengan Program Kemitraan dan Bina Lingkungan yang diatur oleh UUBUM N. Hal ini secara normatif ada nomenklatur pengkategorian yang berbeda antara peristiwa hukum yang diatur. Persoalan ini belum terjawab oleh keluarnya Peraturan Pemerintah No 47 Tahun 2012 yang merupakan petunjuk teknis dari UUPT untuk pelaksanaan CSR. Bahkan mempertegas adanya pembedaan seperti yang disebutkan dalam Pasal 2 "Setiap Perseroan selaku subjek hukum mempunyai tanggung jawab sosial dan lingkungan". (Isnaini Muallidin dan Leli Joko Suryono, 2015:128)

Kedua, pelaksanaan CSR maupun PKBL oleh BUMN sama-sama diwujudkan dalam bentuk bantuan sosial dan community develo pment. Sehingga BUM N yang melaksanakan CSR dan PKBL memiliki beban ganda dalam untuk biaya dan pekerjaan yang sama.

Ketiga sumber pendanaan TJLS yang diatur dalam Pasal 74 UUP bersumber dari Anggraan, sedangkan Pelaksanaan PKBLyang diatur dalam Pasal 88 UU BUM N bersumber dari sebagian keuntungan. Hal ini menimbulkan ketidak efisiensinan. Selain itu mekanisme pelaporan PKBL harus dibuat dalam laporan keuangan secara terperinci dan harus diperiksa oleh auditor independen. Sedangkan pelaporan CSR tidak eksplisit diatur mekanismenya. sehingga rawan adanya tumpeng tindah dan penyalahgunaan.

Persoalan diatas menimbulkan perdebatan. Menurut pernyataan Komisi VI DPR RI, BUMN hanya dapat menyalurkan PKBL, bukan CSR. Wakil Ketua Komisi VI DPR RI, H Azam Azman Natawijaya, menyatakan bahwa Program CSR hanya boleh disalurkan oleh perusahaan swasta, sedangan PKBL yang diatur oleh undang-undang dijalankan oleh BUMN. (https://manado.antaranews.com/berita/ 24775/bumn-jangan-keliru-salurkan-csr-dan-pkbl)

Namun kondisi di lapangan, ada perusahaan BUM N yang menyalurkan CSR saja, atau malah menyalurkan keduanya, yaitu PKBL dan CSR. BUM N yang menjalankan kedua hal tersebut antara lain Pertamina dan Kimia Farma. Program Kemitraan dilaksanakan dengan pembinaan usaha kecil mitra binaan di sekitar wilayah operasi Pertamina. Kegiatan Program Bina Lingkungan meliputi pemberian bantuan untuk bencana alam, bantuan pendidikan dan pelatihan, bantuan prasarana umum, bantuan kesehatan masyarakat, bantuan sarana ibadah serta bantuan pelestarian alam. Sedangkan salah satu bentuk CSR Pertamina adalah pemberdayaan masyarakat melalui peningkatan infrastruktur dan Program Pertamina Peduli Bencana Alam. Dalam pembangunan infrastruktur dilakukan perbaikan terhadap sarana umum seperti jalan, jembatan, M CK dan sarana air bersih. (http:// www.pertamina.com, 2017) Selain Pertamina, BUM N yang menjalankan kedua program tersebut adalah PT Kimia Farma Tbk. (http://infopkbl.bumn.go.id/index.php/home/detail/1CSR-Kimia-Farma-di-Ponpes-Persis-Al-Amin-Ciamis). Persoalan ini dimulai ketika (mantan) M enteri BUM N Dahlan Iskan saat mengeluarkan surat keputusan mengenai PKBL. Namun, sebagai tindaklanjut kekeliruan ini, Komisi VI DPR telah meminta kepada M enteri BUM N Rini Mariani Soemarno Soewandi agar mencabut surat keputusan tersebut. (http:// www.dpr.go.id/berita/detail/id/9886).

\section{RUMUSAN MASALAH}

Adanya ketidakjelasan CSR dan PKBL BUM N tersebut menjadi problematikan untuk mengkaji hal-hal sebagai berikut:

1. Bagaimana mekanisme pelaksanaan CSR dan PKBL di Perusahaan BUM N?; dan

2.Bagaimana mekanisme dan bentuk pelaporan CSR dan PKBL di Perusahaan BUM N?

\section{TINJ AUAN PUSTAKA}

\section{A. Tanggung Jawab Sosial Perusahaan (Corporate Social Responsibility)}

Tanggung Jawab Sosial Perusahaan atau sering disebut Corporate Social Responsibility (CSR) adalah komitmen perusahaan untuk berperan serta dalam pembangunan ekonomi berkelanjutan guna meningkatkan kualitas kehidupan dan lingkungan yang bermanfaat, baik bagi perseroan sendiri, komunitas setempat, maupun masyarakat pada umumnya. (Gunawan Widjaya dan Yeremia Ardi Pratama, 2008:48)

Banyak istilah tentang tanggungjawab perusahaan, dalam perundang-undangan menggunakan tanggungjawab sosial dan lingkungan atau corporate social responsibility atau kadangkala orang menyebut juga dengan business social 
responsibility atau corporate citizenship atau corporate responsibility atau business citizenship. Istilah-istilah diatas sama artinya dan sering digunakan untukmerujuk pengertian CSR. (T. Romi M arnelly, 2012:50)

Konsep CSR dipopulerkan pada tahun 1953 dengan diterbitkan buku yang bertajuk "Social Responsibilities of the Businessman" karya Howard R. Bowen yang kemudian dikenal dengan Bapak CSR. (Paparan BUM N, 2010)

Istilah CSR mulai digunakan pada era 1970an dan semakin populer pasca terbitnya buku John Elkington yang berjudul Cannibals With Forks: The Triple Bottom Line in 21st Century Business (1998) dimana Elkington mengemas CSR ke dalam tiga fokus: 3P, singkatan dari profit, planet dan people. Perusahaan yang baik tidak hanya memburu keuntungan ekonomi belaka (profit), melainkan pula memiliki kepedulian terhadap kelestarian lingkungan (planet) dan kesejahteraan masyarakat (people).(Edi Suharto, 2008)

Ruang lingkup CSR menurutJohn Elkington terbagi atas 3 (tiga) aspek yang dikenal dengan istilah "Triple Bottom Line" yang meliputi kesejahteraan atau kemakmuran ekonomi (economic prosperity), peningkatan kualitas lingkungan (enviromental equality) dan keadilan sosial (social justice). (Yusuf Wibisono, 2007:22)

CSR di Indonesia merupakan pelaksanaan dari hukum tentang lingkungan hidup, yang memiliki tiga asas yakni asas tanggung jawab negara, asas berkelanjutan, dan asas manfaat. (Siti Kusumawati Azhari, 2007: 289)

Menurut Lingkar Studi CSR yang disampaikan oleh Asisten Deputi PKBL Kementerian BUM N pada acara Rakor "Penguatan Kerjasama Pengelolaan Peluang Kerja Dan Peluang Usaha", 14-15 November 2010, pengertian CSR adalah "Upaya sungguh-sungguh dari entitas bisnis meminimumkan dampak negatif dan memaksimumkan dampak positif operasinya terhadap seluruh pemangku kepentingan dalam ranah ekonomi, sosial dan lingkungan untuk mencapai tujuan pembangunan berkelanjutan".

Pemahaman tentang CSR pada umumnya berkisar pada tiga hal pokok, yaitu: Pertama, suatu peran yang sifatnya sukarela (voluntary) dimana suatu perusahaan membantu mengatasi masalah sosial dan lingkungan, oleh karena itu perusahaan memiliki kehendak bebas untuk melakukan atau tidak melakukan peran ini; Kedua, disamping sebagai institusi profit, perusahaan menyisihkan sebagian keuntungannya untuk kedermawanan (filantropi) yang tujuannya untuk memberdayakan sosial dan perbaikan kerusakan lingkungan akibat eksplorasi dan eksploitasi. Ketiga, CSR sebagai bentuk kewajiban (obligation) perusahaan untuk peduli terhadap dan mengentaskan krisis kemanusiaan dan lingkungan yang terus meningkat. (T. Romi M arnelly, 2012:52) Pelaksanaan CSR didasarkan pada etika bisnis yang mengacu pada nilai moral, Sehingga dapat diwjibkan hukum, karena hukum dibangun berdasarkan nilai-nilai moral. Untuk itu tidak perlu diperdebatkan lagi. Sebab antara hukum dan moral tidak dapat dilepaskan satu sama lain (M ukti Fajar; 2009). CSR adalah mekanisme bagi suatu organisasi untuk secara sukarela mengintegrasikan perhatian terhadap lingkungan dan sosial ke dalam operasinya dan interaksinya dengan stakeholder, yang melebihi tanggung jawab organisasi di bidang hukum. (Darwin dalam Bagus Prio Prasojo, 2011:13).

Pelaksanaan CSR yang menuntut adanya pertanggungjawaban dari perusahaan kepada masyarakat (sosial) dan lingkungan melanda dunia bisnis secara global, tidak terkecuali di Indonesia. (Agus Purwanto, 2011:12)

Di Indonesia, selain alasan etika bisnis, CSR diimplementasikan sebagai bentuk kepatuhan pada hukum perusahaan yang diatur dalam UUPT. (Wahyu Suparyono, 2012:1) Di tataran legal, UUPT Pasal 74 mewajibkan perusahaan di Indonesia untuk melakukan CSR. UUPT Pasal 74 ayat 1 yang menyatakan bahwa Perseroan Terbatas yang menjalankan usaha di bidang dan/atau bersangkutan dengan sumber daya alam wajib menjalankan tanggung jawab sosial dan lingkungan.

Saat ini, secara umum CSR diatur dalam beberapa peraturan perundang-undangan, yaitu:

a. Undang-Undang Nomor 25 Tahun 2007 tentang Penanaman M odal (Selanjutnya disebut UUPM) Pasal 15 Huruf (b) yang menyatakan bahwa setiap penanam modal berkewajiban melaksanakan tanggung jawab sosial perusahaan. (UUPM, 2007)

b. Undang-Undang Nomor 40 Tahun 2007 tentang Perseroan Terbatas Pasal 74 berbunyi: (UUPT, 2007)

1) Perseroan yang menjalankan kegiatan usahanya dibidang dan atau berkaitan dengan sumber daya alam memiliki kewajiban untuk melaksanakan 
tanggung jawab sosial dan lingkungan.

2) Tanggung jawab sosial dan lingkungan sebagaimana dimaksud pada Ayat (1) merupakan kewajiban perseroan yang dianggarkan dan diperhitungkan sebagai biaya perseroan yang pelaksanaanya dilakukan dengan memperhatikan kepatutan dan kewajaran.

3) Perseroan yang tidak melaksanakan kewajiban sebagaimana dimaksud pada Ayat (1) dikenai sanksi sesuai dengan ketentuan peraturan perundangundangan.

C. Peraturan Pemerintah Nomor 47 tahun 2012 tentang Tanggung Jawab sosial dan Lingkungan (CSR) Perseroan Terbatas

Pengaturan pelaksanaan CSR dalam Pasal 4 PP 47/2012, dikatakan bahwa CSR dilaksanakan oleh Direksi berdasarkan rencana kerja tahunan perseroan setelah mendapat persetujuan Dewan Komisaris atau Rapat Umum Pemegang Saham (RUPS) sesuai dengan anggaran dasar perseroan. Rencana kerja tahunan perseroan tersebut memuat rencana kegiatan dan anggaran yang dibutuhkan untuk pelaksanaan CSR, dengan kata lain sumber dana CSR dianggarkan dan diperhitungkan sebagai biaya Perseroan yang pelaksanaannya dilakukan dengan memperhatikan kepatutan dan kewajaran. (Pasal 74 UUPT, 2007)

Sampai saat ini belum ada ketentuan resmi yang mengatur secara rinci mengenai berapa besaran dana CSR, tiap Perseroan dapat menganggarkan jumlah yang berbeda, sebagai contoh Pertamina menganggarkan dana CSR sebesar 1 (satu) persen dari profit. (https://economy.okezone.com/ read/2012/05/16/320/630803/pertamina-anggarkan-danaCSr-1-dari-profit) Untuk menghitung besaran dana CSR yang dialokasikan bisa diukur dari laba bersih atau besaran keuntungan perusahaan, apakah persentasenya 2,5\% atau $3 \%$ dari keuntungan selama sesuai dengan asas kepatutan dan kewajaran. (https://www.kompasiana.com/andifadlibone/pemerintah-harus-menetapkan-besaran-dana-csr-yangdialokasikan-tiap-perusahaan_5948b5e616ce71722b09e6b2)

Yang dimaksud dengan "kepatutan dan kewajaran" adalah kebijakan Perseroan, yang disesuaikan dengan kemampuan keuangan Perseroan, dan potensi risiko yang mengakibatkan tanggung jawab sosial dan lingkungan yang harus ditanggung oleh Perseroan sesuai dengan kegiatan usahanya yang tidak mengurangi kewajiban sebagaimana yang ditetapkan dalam ketentuan peraturan perundangundangan yang terkait dengan kegiatan usaha Perseroan. (penjelasan PP Nomor 47 tahun 2012)

M eskipun CSR telah diatur oleh Undang Undang, debat mengenai "kewajiban" CSR masih bergaung. Bagi kelompok yang tidak setuju, Undang Undang CSR dipandang dapat mengganggu iklim investasi. Program CSR adalah biaya perusahaan. Di tengah negara yang masih diselimuti budaya KKN (Korupsi, Kolusi, Nepotisme), CSR akan menjadi beban perusahaan tambahan disamping biaya-biaya siluman yang selama ini sudah memberatkan operasi bisnis.(Edi Suharto, 2008:4)

\section{B. Program Kemitraan dan Bina Lingkungan}

Kegiatan Program Kemitraan dan Bina Lingkungan (PKBL) adalah suatu jenis program kepedulian social dan upaya membantu pengusaha kecil yang dilakukan oleh BUM N. PKBLterdiri dari dua jenis Program yakni Program Kemitraan dan Bina Lingkungan. Pemilihan fokus area kedua program tersebut disesuaikan dengan wilayah lokasi dimana suatu BUMN beroperasi. (https://www.kompasiana.com/ claraayuzilvana/apa-itu-program-kemitraan-dan-binalingkungan-pada-bumn_565ecfe2e7afbd7e09f37896)

PKBL diawali dengan penetapan Peraturan Pemerintah No. 3 tahun 1983, ketika itu namanya Pembinaan Usaha Kecil (PUK). Setelah berjalan enam tahun, pada 1989 PUK berganti nama menjadi Pegelkop singkatan dari Pembinaan Pengusaha Ekonomi Lemah dan Koperasi melalui Keputusan Menteri Keuangan Nomor: 1232/KM K.013/1989 tanggal 11 November 1989 tentang Pedoman Pembinaan Pengusaha Ekonomi Lemah dan Koperasi melalui BUM N. (Ferdian Septa, 2016:8)

Program Kemitraan BUM N dengan Usaha Kecil, yang selanjutnya disebut Program Kemitraan, yaitu program untuk meningkatkan kemampuan usaha kecil agar menjadi tangguh dan mandiri melalui pemanfaatan dana dari bagian laba BUM N. Sedangkan Program Bina Lingkungan, yang 
selanjutnya disebut Program BL, yaitu program untuk membentuk calon Mitra Binaan baru dan pemberdayaan kondisi sosial masyarakat oleh BUM N melalui pemanfaatan dana dari bagian laba BUMN. Program BL ini bersifat bantuan (Korban Bencana Alam, Bantuan Pendidikan dan/atau Pelatihan, Bantuan Peningkatan Kesehatan, Bantuan Pengembangan Sarana dan/atau Prasarana dan Bantuan Sarana Ibadah). (bumn.go.id, 2017)

Perum dan Persero dalam melaksanakan Program Kemitraan dan Program Bina Lingkungan wajib memenuhi ketentuan-ketentuan yang diatur dalam Peraturan menteri BUM N, sedangkan BUM N yang berbentuk Persero Terbuka dapat melaksanakan Program Kemitraan dan Program Bina Lingkungan dengan berpedoman pada Peraturan menteri BUM N yang ditetapkan berdasarkan keputusan Rapat Umum Pemegang Saham (RUPS). (Permen BUM N, 2015)

Pengaturan mengenai Program Kemitraan dan Program Bina Lingkungan antara lain sebagai berikut:

a. Pasal 88 Undang Undang Nomor 19 Tahun 2003 tentang Badan Usaha Milik Negara;

b. Peraturan Menteri BUMN Nomor 09/MBU/07/2015 yang telah dirubah dengan Peraturan M enteri BUMN Nomor 03/M BU/12/2016 yang telah dirubah dengan Peraturan Menteri BUM N Nomor 02/M BU/07/2017 tentang Program Kemitraan dan Bina Lingkungan Badan Usaha M ilik Negara

Adapun tujuan dari Program Kemitraan dan Bina Lingkungan (PKBL) adalah sebagai berikut (Permen BUM N 09/M BU/07/2015):

a. Program Kemitraan, adalah program yang bertujuan untuk meningkatkan kemampuan usaha kecil agar menjadi tangguh dan mandiri.

b. Program Bina Lingkungan, yang selanjutnya disebut Program BL, adalah program yang bertujuan untuk pemberdayaan kondisi sosial masyarakat oleh BUMN.

Dana Program Kemitraan dalam PKBL disalurkan dalam bentuk: (Pasal 9 Permen BUMN 09/M BU/07/2015)

a. Pinjaman untuk membiayai modal kerja dan/atau pembelian aset tetap dalam rangka meningkatkan produksi dan penjualan;

b. Pinjaman tambahan untuk membiayai kebutuhan yang bersifat jangka pendek dalam rangka memenuhi pesanan dari rekanan usaha Mitra Binaan;

Sasaran Utama dari program ini adalah para Usaha M ikro, Kecil dan M enengah (UM KM ) yang dapat dikatakan dalam status non-bankable atau belum mendapatkan akses pinjaman modal dari bank, keistimewaannya apabila dibandingkan bank adalah pinjaman yang diberikan suatu entitas PKBL kepada para mitra binaannya hanya dikenakan bunga $6 \%$ flat per tahun dan diberikan pembinaan secara "gratis" baik berupa peningkatan kapasitas dalam bentuk pelatihan dan promosi dalam bentuk keikutsertaan pameran skala nasional atau penyelenggaraan bazaar. (Kompasiana, Apa itu Program Kemitraan dan Bina Lingkungan pada BUM N?, 2015) Setiap calon mitra binaan yang mengajukan pinjaman akan dievaluasi dengan mengacu prinsip $5 \mathrm{C}$ (Character, Capacity, Capital, Collateral, Condition) yang sudah terkenal pada dunia kredit perbankan namun dengan standar yang mungkin tidak seketat perbankan.

Sedangkan dana Program Bina Lingkungan disalurkan dalam bentuk: (Pasal 9 Permen BUM N 02/M BU/07/2017)

a. bantuan korban bencana alam;

b. bantuan pendidikan, dapat berupa pelatihan, prasarana dan sarana pendidikan;

c. bantuan peningkatan kesehatan;

d. bantuan pengembangan prasarana dan/ atau sarana umum;

e. bantuan sarana ibadah;

f. bantuan pelestarian alam; dan/atau

g. bantuan sosial kemasyarakatan dalam rangka pengentasan kemiskinan, termasuk untuk:

1) elektrifikasi di daerah yang belum teraliri listrik;

2) penyediaan sarana air bersih;

3) penyediaan sarana M andi Cuci Kakus;

4) bantuan pendidikan, pelatihan, pemagangan, promosi, dan bentuk bantuan lain yang terkait dengan upaya peningkatan kemandirian ekonomi usaha kecil selain Mitra Binaan Program Kemitraan;

5) perbaikan rumah untuk masyarakat tidak mampu;

6) bantuan pembibitan untuk pertanian, peternakan dan perikanan; atau

7) bantuan peralatan usaha.

Sumber pendanaan PKBL merupakan pemanfaatan dana dari bagian laba BUMN. Jumlah penyisihan laba untuk 


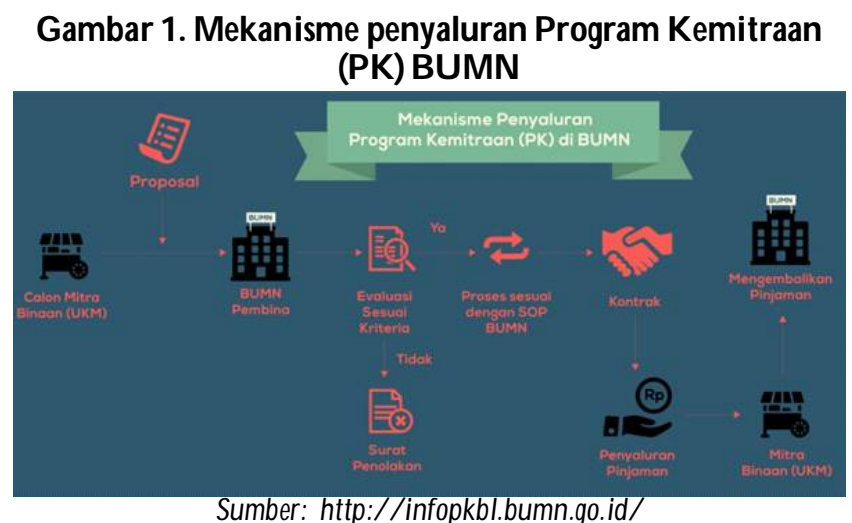

Gambar 2. Mekanisme penyaluran program Bina Lingkungan (BL) BU MN

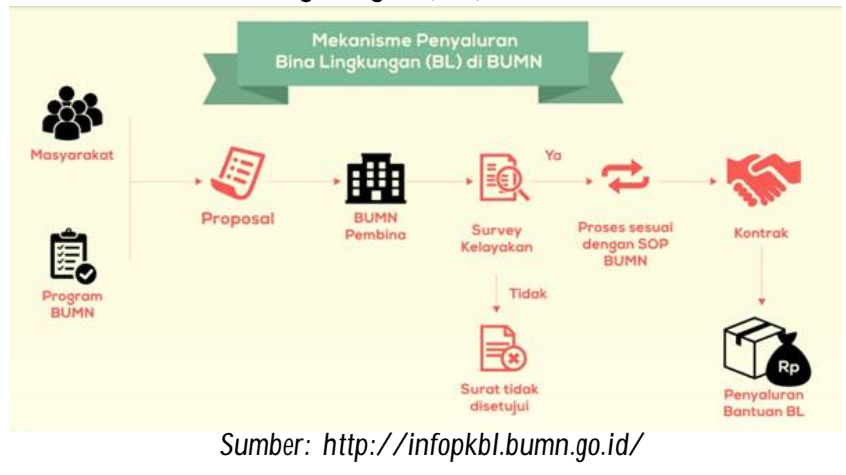

pendanaan program maksimal sebesar $2 \%$ (dua persen) dari laba bersih untuk Program Kemitraan dan maksimal 2\% (dua persen) dari laba bersih untuk Program Bina Lingkungan. (bumn.go.id, 2017)

Pasal 8 Peraturan Menteri BUM N Nomor 03/M BU/12/ 2016 menyatakan bahwa sumber Dana Program Kemitraan dan Bina Lingkungan adalah sebagai berikut:

a. Penyisihan sebagian laba bersih BUM N; dan/ atau

b. Anggaran yang diperhitungkan sebagai biaya pada BUMN.

C. Selain sumber dana sebagaimana di atas, dana Program Kemitraan juga bersumber dari:

1) saldo dana Program Kemitraan yang teralokasi sampai dengan akhir tahun 2015;

2) jasa administrasi pinjaman/marjin/bagi hasil, bunga deposito dan/atau jasa giro dari dana Program Kemitraan; dan/atau

3) pelimpahan dana Program Kemitraan dari BUM N lain, jika ada. d. Selain sumber dana sebagaimana disebutkan diatas, dana Program BLjuga bersumber dari:

1) saldo dana Program BL yang teralokasi sampai dengan akhir tahun 2015;

2) hasil bunga deposito; dan/atau

3) jasa giro dari dana Program BL yang masih tersisa dari dana Program BL tahun sebelumnya, jika ada.

Penerapan Program Kemitraan dan Bina Lingkungan terlihat dalam gambar 1 dan Gambar 2.

\section{Reflexive law theory}

Sampai saat ini, belum ada peraturan organik yang merupakan turunan dari berbagai undang-undang tersebut yang mengikat secara pasti dalam bentuk peraturan pelaksanaan mengenai CSR. Bila dilihat dari pada implementasinya, maka CSR cenderung dilakukan sesuai dengan konsep self regulatory. (https://sites.google.com/site/ myrefresing82/corporate-social-responsibility-csr)

Ditinjau dari aspek hukum, terdapat beberapa teori tentang regulasi CSR, yaitu social responsibility theory, Hobbesian Leviatan theory, corporate governance theory, dan reflexive law theory. (M ukti Fajar, 2010: 34)

David Hess menawarkan Reflexive Law Theory sebagai pendekatan untuk mencari jalan keluar bagi regulasi CSR. Korporasi diberi kewajiban untuk mengatur dirinya sendiri dalam memperhatikan persoalan sosial dan memberikan laporan kepada masyarakat (pasar), dan selanjutnya, biarlah masyarakat (pasar) yang akan memberikan penilaian. (Mukti Fajar, 2009:380)

M eskipun teori ini memberikan kebebasan pada korporasi dalam menjalankan program CSR, akan tetapi tetap harus ada transparansi dari laporan keuangan perusahaan. Sesuai Reflexive Law Theory, laporan tersebut juga disampaikan kepada masyarakat umum dalam bentuk social reporting sehingga masyarakat dapat melakukan penilaian secara lebih objektif terhadap kinerja CSR korporasi.(Mukti Fajar, 2009:401) halamannya belum

Laporan tersebut sebagai bentuk tanggung jawab hukum berupa social accounting, auditing dan reporting bagi stakeholder, yang disebut dengan social reporting (Mukti Fajar, 2010: 39) 


\section{METODE PENELITIAN}

Penelitian ini merupakan penelitian yuridis normatif dan empiris. Penelitian hukum normatif adalah penelitian hukum yang dilakukan dengan meneliti bahan hukum berupa peraturan perundang-undangan, artikel jurnal ilmiah, buku buku dan dokumen hukum lainnya. Dalam penelitian ini, yang dikaji adalah ketentuan hukum positif mengenai CSR dan PKBL yaitu UUPT, UUBUMN dan Peraturan Menteri BUMN Nomor 09/M BU/07/2015 yang telah dirubah dengan peraturan menteri BUM N Nomor 03/ M BU/12/2016 dan Nomor 02/ M BU/7/2017 tentang Program Kemitraan dan Bina Lingkungan Badan Usaha M ilik Negara. Sedangkan penelitian hukum empiris dilakukan untuk melihat pelaksanaan dari Tanggung jawab social dan PKBL yang telah dilakukan oleh beberapa perusahaan BUM N

\section{HASIL PENELITIAN DAN ANALISIS}

\section{A. Pelaksanaan Tanggung Jawab Sosial Perusahaan dan Program Kemitraan Bina Lingkungan Badan U saha Milik Negara}

\section{A.1. Tanggung Jawab Sosial Perusahaan BUMN}

Pada BUMN, sebagai bentuk tanggungjawab sosial, terdapat kewajiban untuk melaksanakan Program Kemitraan dan Bina Lingkungan, akan tetapi diluar itu, BUM N tetap dapat menyalurkan bantuan dalam bentuk Corporate Social Responsibility.

Pelaksanaan corporate social responsibility di beberapa BUM N, antara lain sebagai berikut:

1) Perusahaan BUM N, PT Penjaminan Infrastruktur Indonesia (PII) menggelar program Corporate Social Responsibility (CSR) yang menyasar warga di wilayah yang terdampak proyek infrastruktur pemerintah, antara lain di Jabodetabek dan Garut, Serang, Manado dan Balikpapan, dimana sebagian besar merupakan tempat proyek PT PII berada. ${ }^{1}$

2) PTAdhi Karya. Aktivitas CSR ADHI sepanjang tahun 2015 memiliki nilai total sebesar Rp.2.139.792.230. Kegiatan CSR diwujudkan dalam beberapa bentuk, yaitu pemberian beasiswa untuk dua orang siswa kurang mampu yang berprestasi untuk belajar di Akademi Siswa Bangsa Internasional (ASBI), ${ }^{2}$ mengurangi angka kematian anak dan meningkatkan kesehatan ibu hamil dan pemeliharaan tanaman penghijauan kawasan Banjir Kanal Timur (BKT) bekerja sama PT BUM N Hijau Lestari

3) PT Kimia Farma menyerahkan CSR (Corporate Social Responsibility) kepada murid SM A yang kurang mampu kepada siswa-siswi yang dinilai kurang mampu dan berprestasi di SM A Perguruan Ksatria yang beralamatkan di J Percetakan Negara No. D 232, J akarta Pusat. Bantuan berupa uang SPP selama satu semester kepada 7 siswasiswi sekolah tersebut. ${ }^{3}$

4) PLN, melaksanakan CSR nya melalui beberapa program, antara lain program Peningkatan Mutu Pendidikan M asyarakat, terdiri dari Semangat Belajar dari Gunung Suling (PLN Transmisi Jawa Bagian Tengah), Peningkatan Mutu Kesehatan M asyarakat yaitu program Jembatan Kehidupan di Ende (PLN UIP Nusa Tenggara), dan Jamban Sehat Bebas Penyakit (PLN Distribusi J awa Tengah dan D.I.Yogyakarta) ${ }^{4}$

5) Bank Mandiri bersama dengan Perhutani, PT Perikanan Indonesia (Persero) lakukan revitalisasi lahan tambak seluas 17.2 hektar di kawasan Muara Gembong, Bekasi, Jawa Barat. ${ }^{5}$ Bank M andiri juga memberikan pembiayaan petambak, melalui skema KUR.

6) ANTAM bekerjasama dengan masyarakat di Desa Cimande untuk melakukan upaya memperbaiki lahanlahan kritis dengan menanam pohon Jabon di Desa Cimande, Kecamatan Caringin, Kabupaten Bogor, Jawa Barat. ANTAM mengalokasikan dana sebesar 129 juta rupiah untuk kegiatan penanaman dan perawatan tanaman selama 3 tahun. Program ini selain menjadi bagian CSR Lingkungan perusahaan terhadap masyarakat sekitar tambang juga sebagai bentuk partisipasi ANTAM dalam upaya mendukung program One Billion Indonesia Trees (OBIT). ${ }^{6}$

Dari berbagai pelaksanaan CSR BUM N tersebut diatas, program kegiatannya dilakukan dalam bentuk bantuan (Philantrophi) dan sumbangan (Charity), baik kepada masyarakat langsung, infrastruktur maupun pelestarian lingkungan hidup. Walaupun beberapa diantaranya dilakukan untuk pemberdayaan masyarakat (community development). 


\section{A.2. Program Kemitraan dan Bina Lingkungan}

Peran PKBL BUM N mempunyai cakupan yang lebih luas dibanding praktek CSR yang dilakukan oleh perusahaan swasta karena PKBL BUM N juga diharapkan untuk mampu mewujudkan 3 pilar utama pembangunan (triple tracks) yang telah dicanangkan pemerintah dan merupakan janji politik kepada masyarakat, yaitu: (Paparan BUM N, 2010)

a. pengurangan jumlah pengangguran (pro-job);

b. pengurangan jumlah penduduk miskin (propoor), dan;

c. peningkatan pertumbuhan ekonomi (pro-growth). Pelaksanaan Program Kemitraan dan Bina Lingkungan yang dilaksanakan oleh BUM N, antara lain sebagai berikut: 1) Pelaksanaan program PKBL Bank Mandiri salah satunya adalah melalui program Perhutanan Sosial Muara Gembong. Program ini berbentuk sistem pengelolaan hutan lestari yang dilaksanakan dalam kawasan hutan negara kelolaan Perhutani. Program dilaksanakan oleh Masyarakat dalam bentuk Izin Pemanfaatan Hutan.

2) Pelaksanaan program PKBLoleh Perum Perhutani, berupa penyaluran pinjaman dana kemitraan dengan ketentuan sebagai berikut: ${ }^{2}$

a. Kriteria sasaran penyaluran dana pinjaman program kemitraan Perhutani untuk usaha kecil menengah adalah kegiatan ekonomi rakyat skala kecil, kekayaan bersih maksimal Rp. 500 juta (tidak termasuk tanah dan bangunan) atau mereka yang memiliki omzet tahunan maksimal Rp 2.5 milyar, dan kegiatan usahanya telah dilakukan minimal 1 (satu) tahun serta mempunyai potensi dan prospek usaha bersifat produktif untuk dikembangkan.

b. Sedangkan sasaran kelembagaan atau perorangan yang diprioritaskan adalah:

a) Lembaga M asyarakat Desa Hutan (LMDH)

b) Badan Usaha Koperasi LM DH

c) LMDH atau anggota LMDH (telah mendapat pinjaman $\mathrm{PKBL}$, berpotensi mengembangkan usaha pembuatan dan pengadaan pupuk, pembibitan dan lainnya yang dapat menunjang usaha Perhutani)

d) Keluarga $M$ andor Perhutani (mempunyai usaha produktif, tidak menjadi anggota LMDH).

3) PTPN III (Persero) kembali menyalurkan bantuan dalam program bina lingkungan yang diserahkan pada tanggal 12 Desember 2017 di Aula Kelapa Sawit PTPN III Jalan Sei Batanghari Medan kepada penerima bantuan sebanyak 52 objek yang bervariasi seperti renovasi rumah ibadah dan sekolah dengan total bantuan Rp 1,7 milyar. ${ }^{9}$

4) Perkebunan Nusantara VII menggelar pelatihan manajemen usaha kecil bagi mitra binaan PKBL wilayah Lampung, Sumatera Selatan dan Bengkulu. Pelatihan ini bertujuan untuk membina para mitra binaan agar dapat mengelola usaha dengan baik. ${ }^{10}$

5) PKBL Pertamina dengan program sebagai berikut: (http:/ /www.pertamina.com/social-responsibility/pkbl/)

a. Program Kemitraan berupa pembinaan kepada lebih kurang 96.000 mitra binaan usaha kecil dengan total nilai pinjaman mencapai kurang lebih Rp 2,046 triliun;

b. Program Bina Lingkungan Pertamina berupa pemberian bantuan kepada masyarakat di sekitar wilayah operasi Perusahaan, meliputi pemberian bantuan untuk bencana alam, bantuan pendidikan dan pelatihan, bantuan prasarana umum, bantuan kesehatan masyarakat, bantuan sarana ibadah serta bantuan pelestarian alam, Pelatihan Guru dengan TEQIP (Teacher Quality Improvement Program), Bedah Desa M andiri Pertamina yang dibuka di Desa Klamono dan Salawati Sorong, Program Deteksi Dini Kanker Serviks, Bhakti Sosial dan MP3D (Mitra Pertamina Penggerak Pembangunan Desa), Program Beasiswa Khusus dan sebagainya.

Bentuk Kegiatan PKBL terlihat lebih spesifik dan terukur dibandingkan dengan kegiatan CSR BUM N. Formulasi pemberdayaan masayarakat sangat Nampak dalam bentuk pemberian bantuan modal bergulir atau pinjaman kredit usaha ringan. Bentuk pendampingan usaha kecil agar mandiri juga ditujukan agar masyarakat yang mendapat bantuan dapat menlanjutkan usahanya secara mandiri.

\section{B. Bentuk Pelaporan Tanggung CSR dan PKBL}

B.1. Mekanisme pelaporan CSR BUMN 
Pengungkapan tanggung jawab sosial atau sering disebut sebagai Corporate Social Reporting adalah proses pengkomunikasian efek-efek sosial dan lingkungan atas tindakan-tindakan ekonomi perusahaan pada kelompokkelompok tertentu dalam masyarakat dan pada masyarakat secara keseluruhan (Rosmasita, dalam Bagus Prio Prasojo, 2011:16). Jadi agar bentuk tanggung jawab sosial yang telah dilakukan oleh perusahaan dapat diketahui oleh berbagai pihak yang berkepentingan, maka hal itu diungkapkan dalam laporan tahunan perusahaan.(Bagus Prio Prasojo, 2011:16). Penyediaan informasi yang luas dalam laporan keuangan merupakan keharusan yang disebabkan adanya permintaan berbagai pihak yang berkepentingan dalam informasi tersebut. (Ari Kamayanti)

Hendriksen mendefinisikan pengungkapan sebagai penyajian sejumlah informasi yang dibutuhkan untuk pengoperasian secara optimal pasar. Pengungkapan ada yang bersifat wajib (mandatory), yaitu pengungkapan informasi wajib dilakukan oleh perusahaan yang didasarkan pada peraturan atau standar tertentu. Tetapi ada juga yang bersifat sukarela (voluntary) yang merupakan pengungkapan informasi melebihi persyaratan minimum dari peraturan yang berlaku. (Hendriksen dalam Bagus Prio Prasojo, 2011:18)

Kewajiban pelaporan CSR di Indonesia telah diatur secara normative wajib dimuat dalam laporan tahunan Perseroan dan dipertanggungjawabkan kepada RUPS. (Pasal 6 PP Nomor 47 tahun 2012). Dari ketentuan tersebut, dapat kita simpulkan bahwa pertanggungjawaban pelaporan CSR cukup di hadapan Rapat Umum Pemegang Saham (RUPS) dan tidak ada ketentuan lebih lanjut mengenai kewajiban untuk di audit.

Namun pelaporan CSR juga merupakan bagian dari suatu laporan keuangan tahunan (annual report), beberapa laporan tahunan CSR memiliki sistematika sebagai berikut: (Annual Report PT Semen Padang 2014)
a. Pendahuluan;
b. Visi Misi CSR
c. Kebijakan CSR
d. Profil pengelola CSR
e. Strategi dan Anggaran CSR
f. Pelaksanaan program CSR (jenis program, kegiatan- kegiatan CSR beserta dokumentasi)

\section{g. Rencana CSR tahun berikutnya}

Selain itu mekanisme pelaporan CSR juga telah diatur dalam beberapa self regulation, antara lain adalah pernyataan Ikatan Akuntan Indonesia (IAI) sebagaimana dinyatakan dalam Pernyataan Standar Akuntansi Keuangan (PSAK) No. 1 (Revisi 1998) Paragraf kesembilan:

“Perusahaan dapat pula menyajikan laporan tambahan seperti laporan mengenai lingkungan hidup dan laporan nilai tambah (value added statement), khususnya bagi industry dimana faktor-faktor lingkungan hidup memegang peranan penting dan bagi industry yang menganggap pegawai sebagai kelompok pengguna laporan yang memegang peranan penting"

Saat ini sustainability report perusahaan-perusahaan hampir di seluruh dunia disusun dengan mengunakan standar pelaporan yang diusulkan oleh GRI (Global Reporting Initative). (Bagus Prio Prasojo, 2011:19) Global Reporting Initiative menekankan pentingnya enam prinsip yang perlu diperhatikan dalam membuat pelaporan CSR yang baik (Sukada dan Jalal dalam Edi Suharto, 2008:9):

a. Accuracy: informasi haruslengkap dan cukup detail agar bisa dinilai oleh pemangku kepentingan secara jelas, tepat dan akurat.

b. Balance: seimbang yang mencerminkan aspek-aspek positif dan negatif dari kegiatan CSR yang dilakukan.

c. Comparability: aspek atau variabel yang digunakan dan dilaporkan harus konsisten sehingga dapat dibandingkan antar waktu.

d. Clarity: informasi harus tersedia dalam bentuk yang mudah dipahami dan bisa diakses oleh pemangku kepentingan.

e. Reliability: informasi harus ajeg dan terpercaya yang dikumpulkan, direkam, dianalisis dan disajikan berdasarkan cara atau metodologi yang dapat dipertanggung jawabkan.

f. Timeliness: laporan dibuat secara reguler dan tersedia tepat waktu bagi pemangku kepentingan dan pihak-pihak lain yang memerlukan.

\section{B.2. Mekanisme Pelaporan PKBL BUMN}

Dikarenakan dalam pelaksanaannya dibiayai oleh sumber dana yang berbeda, maka sistematika pelaporan CSR dan 
PKBL juga memiliki bentuk yang berbeda.

Mengenai kewajiban pelaporan PKBL oleh BUM N, Pasal 5 huruf i Peraturan M enteri BUM N Nomor 09/M BU/07/2015 menyatakan bahwa BUMN Pembina berkewajiban menyampaikan laporan pelaksanaan Program Kemitraan dan Program BLsecara berkala kepada M enteri.

Selain itu, laporan PKBL memiliki kewajiban diaudit dan memperoleh pengesahan dari menteri BUM N sebagaimana diatur dalam Pasal 17 dan 18 Peraturan Menteri BUM N Nomor 09/M BU/07/2015, yang berbunyi sebagai berikut:

a. Setiap BUMN Pembina wajib menyusun laporan pelaksanaan Program Kemitraan dan Program BL

b. Laporan pelaksanaan Program Kemitraan dan Program BL terdiri dari Laporan Triwulanan dan Laporan Tahunan

c. Laporan pelaksanaan Program Kemitraan dan Program BL sebagaimana dimaksud pada ayat (1) menjadi satu kesatuan dengan Laporan Triwulan dan Laporan Tahunan BUM N Pembina yang dituangkan dalam bab tersendiri

d. Pelaksanaan Program Kemitraan dan Program BL diaudit bersamaan dengan audit Laporan Keuangan BUMN Pembina.

e. Pengesahan Laporan Program Kemitraan dan Program BL menjadi satu kesatuan dengan Pengesahan Laporan Tahunan BUM N Pembina yang bersangkutan.

f. Pengesahan Laporan Tahunan Program Kemitraan dan Program BL sekaligus memberikan pelunasan dan pembebasan tanggung jawab (acquite at de charge) kepada Direksi dan Dewan Komisaris/Dewan Pengawas atas pengurusan dan pengawasan Program Kemitraan dan Program BL

Laporan PKBL sesuai ketentuan Peraturan M enteri BUM N Nomor 18/ MBU/10/2014 tentang Penyampaian Data, Laporan, dan Dokumen Badan Usaha M ilik Negara secara Elektronik, disampaikan dalam bentuk sebagai berikut:

a. Laporan berkala kepada Menteri BUMN/RUPS sebagaimana diatur dalam peraturan perundangan yang wajib disampaikan secara elektronik dan menggantikan penyampaian laporan dalam bentuk asli tercetak (berbasiskertas);

b. Data dan dokumen PKBL yang diperlukan Menteri/RUPS diunggah dalam konten Sistem Informasi Kementerian
BUMN.

Sistematika laporan PKBL BUM N adalah sebagai berikut: (Laporan PKBL Bank M andiri 2015, Laporan PKBL PTPN IV 2016)

a. Surat Pernyataan Tanggung Jawab atas Laporan Tahunan Program Kemitraan dan Bina Lingkungan (PKBL) yang ditandatangani oleh Direksi/ yang mewakili;

b. Laporan auditor independen, berisi pernyataan auditor dan opini mengenai laporan keuangan PKBL;

c. Laporan Posisi Keuangan, berisi posisi aset (kekayaan) dan liabilitas (kewajiban);

d. Laporan Aktivitas PKBL, berisi tentang pendapatan tahunan, beban tahunan, kenaikan atau penurunan aset netto PKBL;

e. Laporan Arus Kas PKBL, berisi pengembalian dana PKBL dari Mitra Binaan dan BUM N Pembina lain, beban PKBL, kenaikan (atau penurunan) kas PKBL;

f. Catatan Atas Laporan Keuangan PKBL, berisi mengenai: 1) Informasi umum mengenai BUM N dan PKBLBUM N;

2) Kegiatan $P K B L$;

3) Sumber dana PKBL;

4) Nama pengelola PKBL;

5) Dasar penyajian laporan keuangan (menggunakan standar akuntansi entitas tanpa akuntabilitas publik/ SAKETAP)

6) Saldo kas PKBL di Bank

7) Piutang PKBL dan penggolongan kualitas pinjaman (lancar, kurang lancar, macet, etc)

8) Penyelesaian laporan keuangan, berisi pernyataan bahwa laporan keuangan telah selesai dan disetujui untuk diterbitkan

\section{KESIM PULAN}

Berdasarkan uraian di atas, dapat disimpulkan beberapa poin dalam kajian ini:

1. Apabila dilihat dari sumber pendanaan, CSR berasal anggaran dan diperhitungkan sebagai biaya Perseroan yang pelaksanaannya dilakukan dengan memperhatikan kepatutan dan kewajaran. (Pasal 74 UUPT, 2007), dimana saat ini belum ada ketentuan berapa persen angka yang dianggap wajar sehingga tiap Perseroan dapat menganggarkan nominal CSR dengan angka yang 
berbeda-beda. Sedangkan sumber dana PKBL bersumber dari sebagian laba bersih BUM N yang disisihkan untuk keperluan pembinaan usaha kecil/koperasi serta pembinaan masyarakat sekitar BUMN (Pasal 88 UUBUM N). Pelaksanaan CSR BUM N dilakukan dengan berbagai kegiatan yang lebih bersifat bantuan dan sumbangan. Bentuk kegiatan CSR bisa lebih luas karena tidak ada pedoman yang ketat. Sedangkan pelaksanaan PKBL BUMN dilaksanakan berdasarkan pedoman peraturan yang detail.

2. Sistem pelaporan CSR dan PKBL memiliki bentuk yang berbeda, dimana pelaporan CSR hanya dimuat dalam laporan tahunan Perseroan dan dipertanggungjawabkan kepada RUPS. Pengungkapan CSR kepada publik di dalam laporan tahunan atau laporan terpisah adalah untuk mencerminkan tingkat akuntabilitas, responsibilitas, dan transparansi perusahaan kepada investor dan stakeholder lainnya. Sedangkan tujuan pelaporan keuangan Program Kemitraan dan Bina Lingkungan adalah menyediakan informasi posisi keuangan, aktivitas dan laporan arus kas serta catatan atas laporan keuangan yang bermanfaat bagi pengguna dalam pengambilan keputusan. Laporan keuangan juga merupakan wujud pertanggungjawaban manajemen dalam mengelola sumber daya yang telah dipercayakan kepadanya serta merupakan indikator penilaian kesehatan BUMN Pembina. Pelaporan harus melalui proses audit oleh auditor independen dan pengesahan oleh Menteri BUMN sebagai bentuk pertanggungjawaban pendanaan yang menggunakan laba dan anggaran BUM N.

\section{CATATAN AKHIR}

1 https:/ / www.merdeka.com/ uang/ program-csr-bumn-ini-sasar-warga-terdampak-proyek-infrastruktur.html

2 http:// www.adhi.co.id/ sustainable/ csr

3 https:// www.kimiafarma.co.id/ informasi/info-csr/ 282-tim-pkbl-kimia-farma-serahkan-bantuan-spp.html

4 http:// industri.bisnis.com/ read/ 20170907/44/ 687599/ pln-sabet-3-pengh argaan-csr http:/ / www.antam.com/ index.php?option=com_content $\&$ task $=v i e w \&$ I temid $=191 \&$ id $=582 \&$ Ian$\bar{g}=$ id

7 http:// csr.bankmandiri.co.id/ project/ perhutanansosial-muaragembong/

8 http:// www.perhutani.co.id/ csr/ pkbl/

9 http:// infopkbl.bumn.go.id/index.php/ home/ detail/ 2-PTPN -III-Serahkan-Bantuan-PK BL -untuk$M$ asyarakat-Sumut-dan-Pen didikan \#sthash.JIxFX6FK.dpuf

10 http:/ / infopkbl.bumn.go.id/ index.php/ home/ detail/ 1-PK BL -PTPN -VII-G elar-Pelatihan-M itra-Binaan\#sthash.ohDH XXDN.dpuf

\section{DAFTAR PUSTAKA}

Buku

Fajar, Mukti."Tanggung Jawab Sosial Perusahaan, Studi Tentang penerapan C SR Pada Perusahaan M ultinasional, Swasta N asional dan BU M N di Indonesia". Yogyakarta: Pustaka Pelajar. 2009

Fajar, M ukti. "Penerapan Tanggung Jawab Sosial di Indonesia". Yogyakarta: Pustaka Pelajar. 2010

Habib, Adjie. "Status Badan Hukum, Prinsip-Prinsip dan Tanggung jawab Sosial Perseroan Terbatas". Bandung: CV. Mandar Maju. 2008

W ibisono, Yusuf. "M embedah K onsep \& A plikasi C SR", Gresik:Fascho Publishing, 2007

W idjaya, G unawan dan Yeremia A rdi Pratama, "Risiko H ukum \& Bisnis Perusahaan Tanpa CSR", Jakarta: Forum Sahabat, Jakarta, 2008

\section{Publikasi}

Aisyiah Aisiqia, Intan, C hoirul Saleh dan Minto Hadi, "C orporate Social Responsibility (CSR) Sebagai U paya Pemberdayaan M asyarakat Sekitar Pabrik Gula (Studi pada PTPN X Persero PG. K rembong Sidoarjo), Jurnal Administrasi Publik volume I No.5 Tahun 2013

Azhari, Siti Kusumawati, Norma Hukum dan Bisnis Tanggung Jawab Sosial Perusahaan, Jurnal Sosioteknologi Edisi 12 Tahun 6, Desember 2007 D wi Setiawati, Rika dan Budi H ermono, Tinjauan Yuridis Tanggung Jawab Sosial dan Lingkungan (CSR) dan Program K emitraan dan Bina Lingkungan (PK BL) Dalam Pelaksanaannya di badan U saha M ilik N egara (BU M N ), 
Jurnal Novum, 2016

Kamayanti, Ari, M engeksplorasi K epedulian Sosial dan Lingkungan PT. AKR Corporindo Tbk. M elalui laporan CSR (Studi Semiotika dan Indeks Pengungkapan), Sekolah Tinggi IImu Ekonomi Mahardhika

M arnelly, T. Romi, Corporate Social Responsibility (C SR): Tinjauan Teori Dan Praktek Di Indonesia, Jurnal Aplikasi Bisnis, Vol 3 No 12012

Muallidin, Isnaini dan Leli Joko Suryono, M odel Kebijakan Pemerintah Daerah Dalam Pengelolaan Program Tanggung Jawab Sosial Perusahaan B erbasis R egulasi Daerah, Jurnal M edia H ukum Volume $22 \mathrm{No1}$ Juni 2015

Prio Prasojo, Bagus, Pengaruh Corporate Governance Terhadap Tingkat Pelaporan Corporate Social Responsibility (CSR) Pada Perusahaan Pertambangan Yang Terdaftar di Bursa E fek Indonesia, U niversitas Diponegoro Semarang, 2011

Purwanto, A gus. Pengaruh Tipe Industri, U kuran Perusahaan, Profitabilitas Terhadap Corporate Social Responsibility, Jurnal Akuntansi \& Auditing Volume 8/ N 0. 1/ November 2011

Septa, Ferdian, Penerapan C SR (C orporate Social Responsibility) M elalui Program K emitraan dan Bina Lingkungan O leh PT PLN (Persero) Tbk W ilayah Riau dan Kepulauan Riau Cabang Pekanbaru, JO M Fakultas Hukum Volume III Nomor 2, Oktober 2016

Suharto, Edi, M enggagas Standar A udit Program C SR, disampaikan pada acara 6th Round Table Discussion "Menggagas Standar A udit Program C SR: Implementasi U U Perseroan Terbatas", A sosiasi Auditor Internal (AAI), Financial Club Jakarta, 27 Maret 2008

Suparyono, Wahyu, Funds Allocation M apping and Corporate Social Responsibility Program (Program K emitraan Dan Bina Lingkungan Pkbl):C ase in Indonesia, G lobal Journal of Management and Business Research Volume 12 Issue 7 Version 1.0 A pril 2012

Paparan Asisten Deputi PKBL Kementerian BUMN pada acara Rakor "Penguatan Kerjasama Pengel olaan Peluang Kerja Dan Peluang U saha", 14-15 N ovember 2010

Internet

http:/ / www.republika.co.id/ berita/ csr/ tanya-jawab- csr/ 12/ 01/ 09/ Ixiwvu-apa-perbedaan-csr-den ganpkbl)

https:/ / www.kompasiana.com/ claraayuzilvana/ apa-ituprogram-kemitraan-d an-bina-lin gkungan-padabumn_565ecfe2e7afbd7e09f37896

http:/ / bumn.go.id/ perhutani/ halaman/ 162

https:/ / www.pindad.com/ csr-dan-pkbl

http:// infopkbl.bumn.go.id/ index.php/ home/ detail/

1-C SR-K imia-F arma-di-Pon pes-Persis-A I-A min-

Ciamis

https:/ / manado.antaranews.com/ berita/ 24775/ bumn-jangan keliru-sal urkan-csr-dan-pkbl

https:/ / economy.okezone.com/ read/ 2012/ 05/ 16/

320/630803/ pertamina-anggarkan-dana-csr-1-dariprofit

https:/ / www.kompasiana.com/ andifadlibone/ pemerintah-harus-menetapkan-besaran-dana-csr-yangdialokasikan-tiap-perusahaan_5948b5e616ce71722b09e6b2

http:/ / www.dpr.go.id/ berita/ detail/ id/ 9886)

http:/ / www.pertamina.com/ social-responsibility/ csrprogram/

http:/ / www.pertamina.com/ social-responsibility/ pkbl/

(https:/ / nasional.tempo.co/ read/697026/ pertaminaberi-isyarat-program-csr-nya-bermasal ah)

(https:/ / nasional.tempo.co/ read/ 827568/ kasus-danacsr-di-sulteng-ini-penjelasan-pt-val eindonesia)

(https:// news.detik.com/ berita/ d-3440899/ kpkminta-pemda-hati-hati-pakai-dana-csr)

https:/ / sites.google.com/ site/ myrefresing82/ corporatesocial-responsibility-csr

Peraturan perundang-undangan

U ndang U ndang N omor 19 tahun 2003 tentang Badan U saha Milik N egara

U ndang-U ndang Nomor 25 Tahun 2007 tentang Penanaman Modal

U ndang U ndang N omor 40 tahun 2007 tentang Perseroan Terbatas

Peraturan Pemerintah Nomor 47 tahun 2012 tentang Tanggung Jawab sosial dan Lingkungan (C SR) Perseroan Terbatas

Peraturan Menteri BU MN Nomor 18/ M BU / 10/ 2014 tentang Penyampaian Data, Laporan, dan D okumen 
Badan U saha M ilik N egara secara Elektronik

Peraturan M enteri BU M N Nomor 09/ MBU / 07/ 2015 yang telah dirubah dengan Peraturan M enteri BU M N Nomor 03/ M BU / 12/ 2016 yang telah dirubah dengan Peraturan Menteri BUMN Nomor 02/ M BU / 07/ 2017 tentang Program Kemitraan dan Bina Lingkungan Badan U saha M ilik N egara

Annual Report PT Semen Padang 2014

Laporan PKBL Bank Mandiri 2015

Laporan PKBL PTPN IV 2016 